\title{
Students Internet usage: psychological and pedagogical aspects
}

\author{
Ekaterina Denisova ${ }^{I *}$, Anna Kruchkova $^{I}$, Natalia Klimova $^{I}$, and Eugene Borokhovski ${ }^{2}$ \\ ${ }^{1}$ Don State Technical University, Faculty "Psychology, Pedagogy and Defectology", \\ 344000 Rostov-on-Don, Russian Federation \\ ${ }^{2}$ Concordia University, Department of Education, Systematic Reviews Project Manager, \\ Centre for the Study of Learning and Performance (CSLP), Montreal, Canada
}

\begin{abstract}
The article presents the results of studying the psychological characteristics of students in connection with their digital behavior. Authors assume that digital behavior of students can be associated with the features of their self-awareness, self-appraisal and value-semantic sphere. In addition, the importance of individual components in the hierarchy of educational values is studied in connection with personality characteristics. The study involved 102 people - students specializing in the social sciences and humanities. As a result, the authors found that students' digital behavior in terms of the online presence is associated with their self-awareness, selfappraisal and value-semantic sphere. Students who spend online less than three hours a day will be more active, extroverted and confident in their real life (offline) than those who spend more time online. The importance of individual components in the hierarchy of educational values is associated with the features of self-awareness, self-attitude. Self-appraisal, selfconfidence, sense of independence and high appreciation of one's individuality are associated with a greater intellectual need, a more active and conscious desire to improve their own competence.
\end{abstract}

One of the interesting and important areas of modern psychological research is the study of the Internet activity of young people, the study of its forms of manifestation, its relationship with various personal characteristics and perception of various digital content, as well as the development of diagnostic methods for measuring this activity. A significant part of research on the use of the Internet is associated with the phenomenon of Internet addiction (IA) or dependence on information technology, including gadgets and computer games.

The development and mass introduction of Internet technologies into everyday life itself does not have a long history, and, consequently, studies of associated with it psychological and pedagogical aspects appear as rather new field in science. Nevertheless, it should be noted that American researchers have already begun active development of the issue of IA and Problematic Internet use (PIU). The founders of the study of individual psychological characteristics associated with Internet-dependent behavior were professor of psychology at

\footnotetext{
* Corresponding author: denisovakeith@gmail.com
} 
the University of Pittsburgh at Bratford Kimberly Young, who developed an Internet addiction inventory in 1994, and New York psychiatrist Ivan Kenneth Goldberg [1]. Later, researchers had focused on the studying of the personality of Internet addicts: Allison S.E. in 2006 showed a predominance of schizoid interpersonal tendencies among people prone to online gaming addiction [2]. Caplan S.E. pointed that Internet-dependent players tend to feel lonely with a predominance of such personality traits as introversion [3]. A number of scientists have determined that addiction to video games in children and adolescents has a correlation with the level of hostility and has an effect on social skills and academic achievements [4-6]. The relationship between online gaming addiction and aggression, selfcontrol, narcissistic personality traits was also shown [7, 8]. Ko C. pointed to low self-esteem in people with IA [9]. Parker J. emphasizes the low emotional intelligence of teenagers addicted to online games [10]. Internet addicts have low self-efficacy in real life, in contrast to the virtual world, where they feel fulfilled [11].

The noted facts were also confirmed in the works of Russian scientists. So, Teperik R.F. and Zhukova M.A. found that people with IA suffer from alexithymia, which affects their level of empathy [12]. In the work of A.Yu. Egorova it is noted that adolescent Internet addicts suffer from low self-esteem and depression [13]. Litvinenko O.V., Rybnikov V.Yu. and Yurenkova V.A. associate online gaming addiction with a high level of situational anxiety, high mental stress, disturbance, as well as a decrease in working capacity and vegetative coefficient (Luscher's test) [14]. In addition, a number of researchers in theoretical reviews conclude that based on statistical data various online resources, which contain criminal content, destructive network communities ("death groups"), as well as violent online games, have an adverse effect on youth, contributing to an increase in the level of aggressiveness and hostility [15-17].

Modern scientific literature defines and associates Internet activity with the terms like "Internet use", "problematic Internet use", "cyber behavior"; in the works of Russian psychologists, it is also associated with the terms "digital behavior" and "media behavior" $[3,5,14]$. Despite the fact that the number of studies of the identified problem is growing every year, the questions of how and to what extent the use of the Internet affects personality, which Internet content has the greatest impact and how to take this influence into regarding education and development of children and youth remain open.

In this regard, the aim of our research was to study the psychological characteristics of students in connection with the characteristics of their digital behavior.

The study involved 102 people, students specializing in the social sciences and humanities at the Don State Technical University (Russian Federation).

The hypotheses of the study:

1. Digital behavior of students can be associated with the features of their selfawareness, self-appraisal and value-semantic sphere.

2. The significance of the individual components in the hierarchy of educational values is probably related to certain personality characteristics, as well as the level of selfappraisal and self-awareness.

Research methods:

1. Psychological testing: Self-attitude inventory (S.R. Pantileev); "Personal Differential" test (the St. Petersburg Psychoneurological Research Institute of V.M. Bekhterev); Questionnaire of terminal values (I.G. Senin); Test of life-meaning orientations (D. A. Leontyev).

2. Questionnaire: respondents were asked to indicate their gender, age, average amount of time they spend on the Internet, what Internet resources they use daily.

3. Statistical analysis: The Mann-Whitney U-test; Kruskal-Wallis H-test; Spearman rank correlation coefficient. 
Research results. As a result of processing the answers in the questionnaire, it is established that more than 50 percent $(61 \%)$ of the respondents according to their self-report spend online more than 6 hours a day, $22 \%$ of the respondents spend 3 to 6 hours a day online, $17 \%$ - less than 3 hours a day (Figure 1).

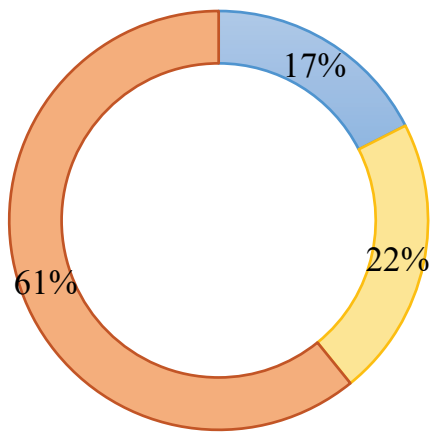

$\square$ less than 3 hours a day

$\square 3$ to 6 hours a day

$\square 6$ hours a day or more

Fig. 1. Self-Report on Internet Usage

The data obtained allowed us to conditionally divide the sample by the degree of respondents' presence on the Internet into at least two subgroups: 1) group 1 - a high degree of online presence (more than 6 hours a day); 2) group 2 - moderate online presence (less than 6 hours a day). By applying the indicated division, we found that some features of students' self-awareness and semantic sphere differ depending on the amount of online presence (Figure 2).

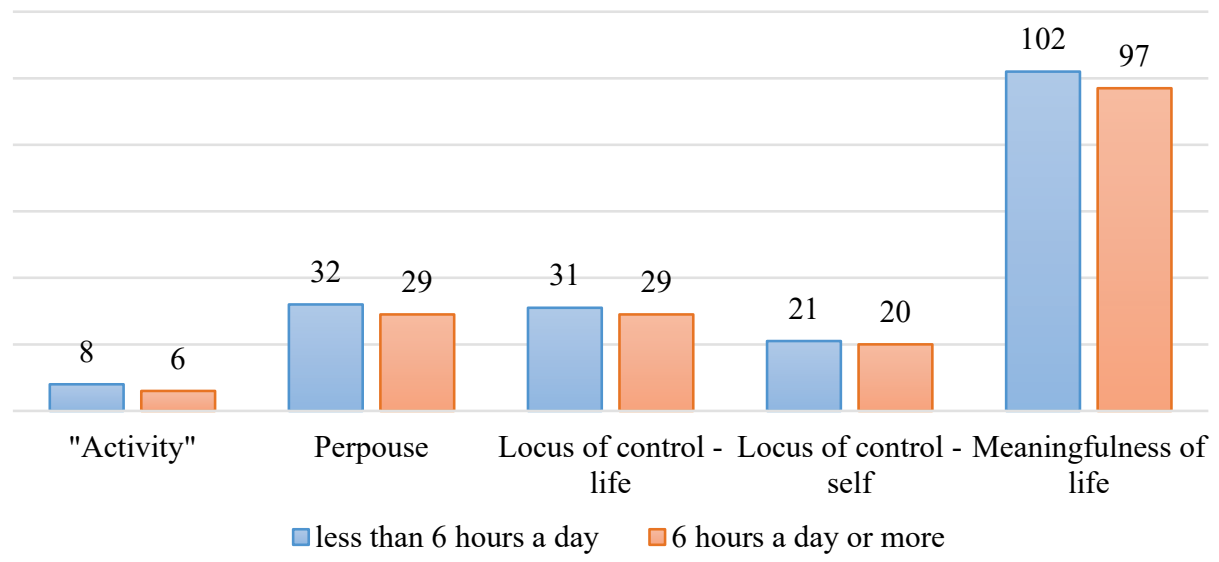

Fig. 2. Study of students' personal characteristics depending on the time spent on the Internet Usage: Mann-Whitney U Test; $\mathrm{p}<0,05$

It was possible to establish that the parameter "Activity" ("Personal Differential" test), a general indicator of the meaningfulness of life and some of its components significantly differ between groups. In the group 1 (respondents spending online more than 6 hours a day), all of these parameters are significantly lower than in the group with an average online presence (group 2). This allowed us to conclude that students who spend less time online are more active, extraverted, self-aware, and motivated. In addition, they have more confidence in themselves and in their ability to control the events of their own lives.

A more detailed analysis of the parameter of respondents' presence on the Internet shows that the "Activity" and "Locus of control - life" are not only increasing with a decrease in 
daily online presence, but also significantly differ among respondents spending 3 to 6 hours a day on the Internet, and those who spends more than 6 hours a day (Figure 3).

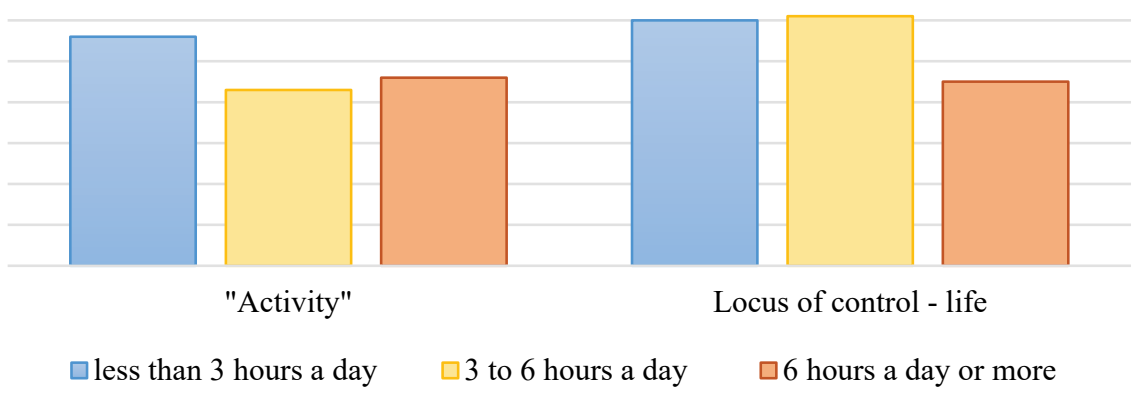

Fig. 3. Study of students' personal characteristics depending on the time spent on the Internet Usage: Kruskal-Wallis ANOVA by Rank; $p<0,05$

The highest mark on the "Activity" scale is observed in the group with the least online presence (less than 3 hours a day), while the lowest is among respondents spending 3 to 6 hours a day on the Internet. It was also found that the highest index of locus of life control is observed in the group with moderate online presence, and the lowest - in the group with highest online presence. At the same time, the groups with low and moderate online presence, despite the high significance of the differences, are quite close in this regard. We can assume that this may be related to characteristics of their digital behavior and quality of the digital communication. It is likely that respondents who spend online less than three hours a day will be more active, extroverted and confident in their real life (offline) than those who spend more time online. However, those who spend much more time online (6 or more hours a day) may have more developed social contacts on the Internet.

Next, we turn to the results of a correlational study of the personality characteristics of students in connection with their educational values (Table 1).

Table 1. The study of the relationship of personal characteristics of students with their educational values: Spearman Rs; $p<0,05$

\begin{tabular}{|l|r|r|r|}
\hline \multicolumn{1}{|c|}{ Variables } & \multicolumn{1}{c|}{ N } & Spearman & p-value \\
\hline Evaluation \& Spiritual Satisfaction & 102 & 0,431 & 0,019 \\
\hline Strength \& High Financial Position & 102 & 0,417 & 0,029 \\
\hline Strength \& Creativity & 102 & 0,327 & 0,022 \\
\hline Strength \& Achievements & 102 & 0,465 & 0,007 \\
\hline Strength \& Spiritual Satisfaction & 102 & 0,455 & 0,010 \\
\hline Activity \& Creativity & 102 & 0,311 & 0,034 \\
\hline Self-confidence \& Spiritual Satisfaction & 102 & 0,491 & 0,003 \\
\hline Self-leadership \& Self-Development & 102 & 0,309 & 0,035 \\
\hline Reflected Self-attitude \& Achievements & 102 & 0,297 & 0,047 \\
\hline Reflected Self-attitude \& Spiritual Satisfaction & 102 & 0,472 & 0,006 \\
\hline Self-worth \& Spiritual Satisfaction & 102 & 0,494 & 0,003 \\
\hline Self-adherence\& High Financial Position & 102 & 0,220 & 0,027 \\
\hline
\end{tabular}


Table 1 shows that the indicators of the "Evaluation" and "Strength" scales (the "Personal Differential" test) have a correlation with the importance of spiritual satisfaction in educational activities. Self-confidence, self-appraisal, and reflected self-attitude also correlate with the latter (Self-attitude inventory). In other words, self-appraisal, selfconfidence, independence and high appreciation of one's individuality are associated with a greater intellectual need, a desire to improve the quality of one's education and a pursuit of a deeper understanding of the subject. Self-confidence and a high assessment of one's own independence (the "Strength" scale) correlate with the importance of creativity, high financial standing and achievements in educational activities as well. Considering the correlations of the listed values with activity, self-attachment and reflected self-attitude, it can be assumed that it is the attitude towards oneself as an independent strong personality that may serve as the basis for the desire to have a level of education that will allow them to have a sufficient level of competence, recognition, high salary and other types wealth. In addition, it is necessary to note the connection between the value of self-development and the indicator of self-leadership (as the ability to direct one's own activity and organize behavior) which can express itself in a more active and conscious desire to improve the level of one's education, as well as in the desire to find something new in the studied discipline, to contribute to a chosen field of knowledge.

Based on the obtained data and analysis, the following conclusions were made:

1. Digital behavior in terms of the online presence of students is associated with their selfawareness, self-appraisal and value-semantic sphere. Students who spend online less than three hours a day will be more active, extroverted and confident in their real life (offline) than those who spend more time online. At the same time, those who spend much more time online (6 or more hours a day) are less self-aware, and motivated, although they may have more developed social contacts online.

2. The importance of individual components in the hierarchy of educational values is associated with the features of self-awareness, self-attitude. Self-appraisal, self-confidence, independence and high appreciation of one's individuality are associated with a greater intellectual need, a more active and conscious desire to increase the level of one's competence.

The results presented, on the one hand, reflect the increasing pace of students' digitalization, and on the other, reflect the personality changes associated with it. It should be noted that in current situation, the online presence is likely to continue to grow rapidly. And this certainly should be taken into account regarding education. In modern society, students, being in an informationally saturated environment, not only do not have the skills to work with so much information flow, but also gradually losing the ability to focus on solving major intellectual tasks. They simply do not have enough time to study and plan their professional future properly. We believe that a modern university should focus on the development of a system of psychological and pedagogical support for professional and personal formation and development of students, while expanding the use of Internet resources in the educational process. Now we are faced with new tasks: first of all, we need to teach them how to navigate the information flow and plan achievement of educational and professional results, preserving the self-awareness, confidence and a sense of purpose, secondly, university should get involved in their daily online presence and help fill their digital environment with educational content.

This research was funded by the Russian Foundation for Basic Research (RFBR), project № 18-2922004.

\section{References}


1. K.S. Young, Addict. Behav, 64, 229-230 (2017)

2. S.E. Allison, L. von Wahlde, T. Shockley, G. O. Gabbard, Am. J. Psychiatry, 163(3), 381-385 (2006)

3. S. Caplan, D. Williams, N. Yee, Comput. Hum. Behav, 25(6), 1312-1319 (2009)

4. D. Alt, M. Boniel-Nissim, Internet Interv, 13, 30-39 (2018)

5. Vanshika Ahuja et al. Procedia Comput. Sci., 122, 671-676 (2017)

6. Siti Zobidah Omar, et al. Procedia Soc Behav Sci, 155, 75 - 80 (2014)

7. S.-I. Chiu, J.-Z.Lee, , D.-H. Huang, Cyberpsychol Behav, 7(5), 571-581 (2004)

8. E. J. Kim, K. Namkoong, T. Ku, S. J. Kim, Eur Psychiatry, 23(3), 212-218 (2008)

9. C.-H. Ko, J.-Y. Yen, C.-C. Chen, S.-H. Chen, C.-F. Yen, J NERV MENT DIS, 193(11), 728-733 (2005)

10. J. D. A. Parker, R. N. Taylor, J. M. Eastabrook, S. L. Schell, L. M. Wood, Pers. Individ. Differ., 45(2), 174-180 (2008)

11. K. Ioannidis, M. S. Treder, S.R. Chamberlain, F. Kiraly, S. A. Redden, D. J. Stein, C. Lochner, J. E. Grant, Addict. Behav, 81, 157 (2018)

12. R. F. Teperik, M. A. Zhukova, Internet addiction: the psychological nature and dynamics of development, 147-149, (2009)

13. A. Yu. Egorov, N. A. Kuznetsova, E. A. Petrova Questions of the psychological health of children and adolescents, 2, 20-27 (2005)

14. V. Yu. Rybnikov, O. V. Litvinenko, V. A. Yurenkova, Psychological determinants of computer game addiction and the features of its prevention, 2, 67-81 (2009)

15. V. K. Kopteva, Communicology, 2(3), 67-74 (2017)

16. M. S. Chvanova, M. S. Anuryeva, I. A. Kiseleva, Bulletin of the Tambov University. Series: Humanities, 22 (5 (169)), 23-36 (2017)

17. A. A. Smirnova, T. Yu. Zakharova, E. S. Sinogina, Pedagogical Review, 3(17), 99-107 (2017) 